GONÇALVES, Marco Antônio. 2001. 0 Mundo Inacabado. Ação e Criação em uma Cosmologia Amazônica. Rio de Janeiro: Editora da UFRJ. 424 pp.

\title{
Oiara Bonilla
}

Doutoranda, Laboratoire d'A nthropologie Sociale (EHESS)

O livro de Marco Antônio Gonçalves é uma etnografia dos Pirahã, povo falante de uma língua mura, constituído por pouco mais de duzentas pessoas que habitam a região entre os rios $M$ armelos e $\mathrm{M}$ aici, ambos afluentes do rio $\mathrm{Ma}$ deira, no sul do Estado do A mazonas. $\mathrm{O}$ autor permaneceu dezoito meses entre os Pirahã e reconstitui aqui seus dados etnográficos em dez capítulos, precedidos por uma introdução onde enuncia suas escolhas teóricas para a análise do material.

O objetivo do autor é "tratar a ação como objeto privilegiado e analisar de que forma o pensamento pirahã a constitui como conceituação cultural específica" (:31). É a partir da ação e de sua descrição em vários contextos que o autor apresenta a cosmologia pirahã, indo do particular (a organização social) ao mais global (o Cosmos).

Os cinco primeiros capítulos abordam a sociologia e a cosmografia pirahã, partindo do "casal" e da "família" como "unidades ordenadoras fundamentais", passando pelo espaço explorado cotidianamente pelos Pirahã e indo até as configurações do Cosmos e de seus diferentes "patamares". Nos últimos cinco capítulos, o autor mostra o mundo "em ação", "em fabricação". A dentramos então os conceitos pirahã e suas percepções sobre o Cosmos.

A principal hipótese de Marco Antônio Gonçalves é que a lógica que rege as distintas classificações dos Pirahã 
é a "lógica da ação". Para ele, a ação é a "relação positiva que supõe por si só pensar todo o Universo através da ótica da troca" (:23), remetendo assim ao problema da reciprocidade. Nesse sentido, "ação é predação e é produção" (:37).

Ainda na introdução, o autor revisita alguns conceitos comuns da disciplina, mais especificamente da etnologia das terras-baixas sul-americanas. Segundo ele, é a ação que constrói a cosmologia, tanto como a cosmologia orienta a ação e a interpretação que se faz sobre ela mesma. Ele discute também a distinção natureza/cultura e seus desdobramentos conceituais (interior/exterior, predador/presa, homem/animal etc.), as teorias sobre corpo e corporalidade, assim como o perspectivismo, sem porém elaborar uma redefinição profunda destes conceitos.

A ação é, portanto, o "motor" da cosmologia. Para sustentar esta hipótese, Gonçalves apóia-se em al guns elementos-chave da etnografia pirahã. 0 primeiro é o mito de recriação do mundo pelo demiurgo Igagai. A flechada dada por um homem à Lua leva o mundo antigo à destruição, e são três mulheres sobreviventes que, de tanto chorar, permitem que o mundo seja recriado por Igagai, dando assim origem aos diferentes seres que o povoam até hoje: os ibiisi, os abaisi, os kaoaiboge e os toipe.

$\mathrm{O}$ autor baseia-se também em alguns princípios constitutivos do pensamento pirahã, como o conceito de "experimento". De fato, todo processo de produção é precedido por tentativas prévias, seja no Cosmos (pelo demiurgo que cria constantemente os animais, por exemplo), seja pelos próprios Pirahã, que fazem modelos e miniaturas de todos os objetos antes de fabricá-los e que apreciam experimentar e provar coisas novas. Outro conceito no qual o autor se apóia é o de "parecer" que "es- tabelece relações entre as coisas e os seres do Cosmos, fazendo surgir um universo de comparações". Assim, "tudo se assemelha", mas "nada é exatamente igual" (:34).

A partir desses dois conceitos e de sua materialização nos seres ibiisi, abai$\mathrm{si}$, kaoaiboge e toipe, o autor apresenta os dados etnográficos e procura finalmente determinar que o que a ação evidencia aqui é a "inconsistência de reciprocidade" (:38), redefinindo as categorias presa/predador e estabelecendo uma "continuidade diferencial" entre os seres, na tentativa de evitar a reprodução de oposições binárias, do tipo natureza e cultura, que ele recusa na introdução. A ação seria responsável tanto pela produção e reprodução, como pela predação, englobando desse modo a vida e a morte. Assim, o universo da ação transformaria a relação pre$\mathrm{sa} /$ predador nos termos presa/presa e predador/predador visto que, "ao sofrer uma ação, a presa classifica seu agressor como presa e não como predador" (:38-39).

Igagai, o principal ser abaisi, demiurgo, morador do patamar superior do Cosmos pirahã, é o responsável pela "fabricação" do mundo atual. Ele refez tudo o que existe hoje no mundo, inclusive os homens. O Cosmos é formado por patamares celestes, terrestres e subterrâneos habitados por vários tipos de seres. O patamar de referência é o dos Pirahã e outros humanos (ibiisi). Os outros patamares são habitados por outros tipos de ibiisi com os quais os $\mathrm{Pi}$ rahã não têm contato, e também por seres abaisi, com exceção do primeiro patamar inferior que abriga também os kaoaiboge e os toipe.

Os ibiisi são os seres humanos: os Pirahã, os brancos e outros índios. Os abaisi são seres antropomorfos imperfeitos, corpos deformados. Eles são o re- 
sultado de uma alteração acidental em um corpo ibiisi. Os abaisi são duplos dos corpos humanos, extensões de seus males físicos. Os abaisi procuram vingarse dos humanos e são responsáveis por suas mortes.

Os kaoaiboge e os toipe são transformações póstumas dos ibiisi. Uma vez morto, o ibiisi liberta um kaoaiboge e um toipe. O primeiro é um espectro pacífico que, após três transformações consecutivas, se torna um jaguar imortal. O segundo é um espectro agressivo e canibal que, após uma segunda transformação em toipe superagressivo e canibal, se transforma, finalmente, em kaoaiboge e segue o mesmo destino escatológico que estes últimos. Os toipe são inimigos dos kaoaiboge e os perseguem para matá-los e devorá-los. Ora os kaoaiboge e os toipe são tidos pelo autor como "espectros" e o abaisi considerado como uma "alma", ora os kaoaiboge e os toipe são "duas almas" de um corpo ibiisi, e o abaisi é seu "duplo" (:198, 202).

Cada patamar é composto pelos mesmos elementos do patamar de referência (animais, vegetais, rios), mas com características e especificidades ecológicas diferentes. A noção de criação e de produção também se encontra reafirmada na pessoa de Igagai que, diariamente, tem de refazer o sol, a lua, e a cada dia manda animais para os humanos se alimentarem.

O que une estes seres é uma substância comum: o etoibii, o sêmen enquanto "substância vital" (:247). A penas os abaisi e as mulheres não o possuem naturalmente. Estas precisam consegui-lo, e é por isso que elas "predam" os homens, para obter etoibii e para completar assim a fabricação do feto (iniciado previamente por um susto levado pela mulher), e predam os animais (a elas incumbe a atividade cine- gética). O autor procura fundamentar a idéia de reversibilidade das posições dos agentes a partir da ação. Ele constrói uma equivalência entre o pênis e o fuso de algodão e entre o sêmen e o algodão. Assim, a mulher retiraria potência dos homens através da relação sexual, mas a restituiria fornecendo algodão para a fabricação do arco-e-flecha.

Um longo e interessante capítulo é dedicado à transcrição de diversos tipos de sonho. O sonho liberta o abaisi (entendido aqui como "alma"), que acessa então a outros planos espaciais e temporais. Os sonhos parecem ocupar o mesmo lugar nessa sociedade amazônica que os mitos ocupam em muitas outras. A mitologia pirahã sendo fragmentária, Gonçalves sustenta que são "os sonhos que elaboram ricamente as regras, as relações e as formas ideais de vida" (:267). De fato, os sonhos que se encontram aqui transcritos mostram a riqueza das elaborações oníricas dos Pirahã. Partindo desta observação, Gonçalves enuncia e analisa os sonhos como se fossem mitos. Multiplicam-se os exemplos, ricos em detalhes, mas não fica claro em que medida é possível (e não problemático) considerar sonhos como mitos; o que isto implica na prática (para os Pirahã), mas também teoricamente (para o autor e para a disciplina).

O objetivo de Gonçalves é mostrar como os sonhos elaboram constantemente a cosmologia e é essa idéia de "construção" e constante "elaboração" que perdura até o final do livro. A mesma idéia está presente no que diz respeito aos animais, à sua fabricação por Igagai e pelos abaisi (nos diferentes patamares do Cosmos) e às suas relações com os humanos. Tudo no Cosmos pirahã é criado, fabricado, replicado, e é a ação "sobre o mundo", a relação entre os agentes, que altera a realidade e cria 
as distinções e classificações sobre ela. Não existe, portanto, posição fixa em uma relação entre termos. O predador que mata uma presa vê-se imediatamente tomado pela posição de presa, já que sua ação vai desencadear a ação de outro. Os animais, vegetais, minerais e inimigos interagem com os Pirahã, não aceitando o lugar de presa. Eles reagem, tornando-se predadores, invertendo assim a cadeia predatória e gerando o que o autor caracteriza como "inconsistência de reciprocidade" (:407). A presa percebe o predador como presa e o predador percebe a presa como predador.

Fica claro que "ação/reação, abaisi/ibiisi, homens/mulheres, pirahã/estrangeiros, são posições intercambiáveis" (:380). O ato é, assim, o "motor" da relação entre todos os seres, estes sendo "equivalentes" porém "não iguais". $\mathrm{O}$ ato desencadeia a interação entre seres e produz transformações ou reproduções em um continuum cosmológico.

O que o autor parece deixar de lado é o fato de essa continuidade entre posições relacionais (presa/presa; predador/predador) não se dar simultaneamente. Não fica claro, por exemplo, que quando a presa categoriza seu predador (após uma agressão) como sua (futura) presa (:38-39), ela se categoriza a si mesma, por sua vez, como (futuro) predador. Portanto, o que o autor introduz aqui é dinâmica e temporalidade no par presa/predador. O fato de o princípio de "inconsistência de reciprocidade" ser enunciado na introdução (:39), mas só ser retomado no final do livro (cap. IX), fecha assim uma argumentação baseada na multiplicação de exemplos etnográficos. À riqueza da etnografia contrapõe-se a falta de uma discussão mais ampla dos conceitos utilizados ("ação”, " presa/predador”, “in- consistência de reciprocidade") que nos permitiria ultrapassar o contexto etnográfico pirahã para pensar ou repensar outras realidades sociocosmológicas. 